\title{
PENGARUH KOMPENSASI DAN KEPEMIMPINAN TERHADAP KEPUASAN KERJA KARYAWAN PT X DI JAKARTA
}

\author{
Italia Bunawan dan Joyce Angelique Turangan \\ Program Studi Manajemen Fakultas Ekonomi Universitas Tarumanagara, Jakarta \\ e-mail: italia.115170234@stu.untar.ac.id
}

\begin{abstract}
Abstrak: Tujuan dari penelitian ini yaitu untuk mengetahui pengaruh dari kompensasi dan kepemimpinan terhadap kepuasan kerja karyawan pada PT X di Jakarta. Pengumpulan data dari sampel dilakukan dengan menggunakan metode cross-sectional design dengan membagikan kuesioner online Google Form. Sampel dikumpulkan dengan metode non-probability sampling berjenis convenience sampling dengan total 100 responden. Metode analisis data yang digunakan yaitu PLS-SEM dan diolah dengan menggunakan software SmartPLS versi 3.3.2. Hasil penelitian ini menunjukkan tidak terdapat pengaruh yang signifikan kompensasi terhadap kepuasan kerja. Sedangkan kepemimpinan memiliki pengaruh yang positif signifikan terhadap kepuasan kerja.
\end{abstract}

Kata Kunci: Kompensasi, Kepemimpinan, Kepuasan Kerja.

Abstract: The purpose of this study is to determine the effect of compensation and leadership on employee job satisfaction at PT X in Jakarta. Data collection from the sample was carried out using a cross-sectional design method by distributing an online Google Form questionnaire. The sample was collected using a non-probability sampling method with a convenience sampling type with a total of 100 respondents. The data analysis method used is PLS-SEM and it is processed using SmartPLS version 3.3.2 software. The results of this study indicate that there is no significant effect of compensation on job satisfaction. Meanwhile, leadership has a significant positive effect on job satisfaction.

Keywords: Compensation, Leadership, Job Satisfaction.

\section{LATAR BELAKANG}

Setiap perusahaan dalam bidang apapun pasti akan membutuhkan dan melibatkan sumber daya manusia dalam melaksanakan berbagai aktivitasnya termasuk untuk mencapai tujuan organisasi atau perusahaan tersebut. Karyawan atau sumber daya manusia menjadi salah satu faktor penentu atas keberhasilan atau kegagalan di suatu perusahaan. Oleh karena itu, setiap perusahaan harus memperlakukan karyawannya sebaik mungkin dan memperhatikan kepuasan kerja dari karyawan tersebut. Kepuasan kerja sendiri merupakan suatu sikap emosional dimana seorang karyawan merasa pekerjaannya menyenangkan dan menyukai pekerjaannya tersebut (Hasibuan, 2006). Menurut Safitri et al., (2014) kepuasan kerja adalah tanggapan emosional dari seorang karyawan terhadap situasi dan kondisi kerja yang dialaminya. Tanggapan emosional tersebut dapat bersifat positif (puas) atau negatif (tidak puas). Karyawan dapat merasakan kepuasan kerja bila sudah membandingkan antara apa yang diharapkan dengan hasil yang diperolehnya dalam pekerjaan tersebut.

Namun terdapat beberapa masalah yang dihadapi oleh PT X dalam upaya meningkatkan kepuasan kerja karyawannya, diantaranya yaitu mengenai pemberian kompensasi dan kepemimpinan dalam perusahaan tersebut. Terdapat dua macam kompensasi yang diberikan 
yaitu kompensasi finansial dan non finansial. Kompensasi finansial yang diberikan berupa gaji, tunjangan, dan insentif. Sedangkan kompensasi non finansial yang diberikan kepada karyawannya yaitu hak cuti, lingkungan kerja yang nyaman, jam kerja yang fleksibel, dan pemberian penghargaan terhadap prestasi yang dimiliki oleh karyawan. Tetapi berdasarkan hasil wawancara dengan karyawan yang bekerja pada PT X menyatakan bahwa kompensasi yang mereka dapat belum sesuai dengan pekerjaan yang mereka kerjakan dalam perusahaan.

Menurut mereka besarnya gaji yang diterima belum sesuai dengan standar gaji yang ditetapkan di DKI Jakarta (UMR) dan tunjangan yang diberikan hanya berupa tunjangan makan dan tunjangan hari raya (THR). Selain itu bagi karyawan yang telah bekerja cukup lama dan telah memberikan kesetiaannya kepada perusahaan masih sulit dalam menerima kenaikan gaji atau promosi jabatan. Sebuah laman pencari kerja, Job Street, menyarankan untuk dapat mempertahankan dan meningkatkan kepuasan kerja karyawan maka perusahaan dapat menyesuaikan besarnya jumlah bonus yang akan diberikan dengan cara mempertimbangkan beberapa faktor seperti kinerja karyawan dan perusahaan dalam jangka waktu 12 bulan terakhir (www.cnnindonesia.com, 2016).

Selanjutnya mengenai kepemimpinan, beberapa karyawan juga mengatakan bahwa mereka kurang menyukai gaya kepemimpinan dari atasan mereka. Menurut mereka terdapat beberapa atasan dari beberapa divisi kurang memberikan motivasi kepada karyawannya dan tidak terlalu mengarahkan mereka untuk meningkatkan kinerjanya serta kurangnya memberikan andil kepada karyawan dalam proses pengambilan keputusan. Bagi mereka, atasan yang dapat meningkatkan kepuasan kerja tidak hanya atasan yang memiliki kepemimpinan tegas dan berwibawa, tetapi juga harus mampu mengayomi karyawannya dengan memberikan motivasi dalam pekerjaan dan dapat melibatkan karyawannya dalam setiap pengambilan keputusan.

Menurut Joshua Siregar, selaku Director National Marketing Dale Carneigie Indonesia, perilaku atasan atau pemimpin pada suatu perusahaan dapat mempengaruhi kepuasan karyawan dalam bekerja dan keinginan mereka untuk bertahan pada perusahaan tersebut. Seorang pemimpin yang bersedia memberi apresiasi, pujian dan menghargai kontribusi karyawan, mau mendengar pendapat karyawan, serta bersedia mengakui kesalahannya merupakan beberapa perilaku yang dapat mempengaruhi kepuasan dari karyawan (www.kompas.com, 2018).

Berdasarkan penjelasan latar belakang di atas, maka penulis tertarik untuk melakukan penelitian dengan judul "Pengaruh Kompensasi dan Kepemimpinan terhadap Kepuasan Kerja Karyawan PT X di Jakarta".

\section{KAJIAN TEORI}

\section{Gambaran Umum Teori}

Teori yang digunakan dalam penelitian ini yaitu teori dua faktor (two factor theory) yang dikembangkan oleh Herzberg. Herzberg menciptakan paradigma dua dimensi tentang faktorfaktor yang dapat mempengaruhi sikap seseorang terhadap pekerjaannya. Kepuasan dan ketidakpuasan yang dirasakan individu terhadap pekerjaannya dipengaruhi oleh faktor yang berbeda (Alshmemri et al., 2017). Kedua faktor tersebut dibagi menjadi dua kelompok kategori, yaitu kategori pertama yang dikaitkan dengan kebutuhan untuk pertumbuhan dan aktualisasi diri yang dikenal sebagai faktor motivasi (motivation factors), sedangkan kategori kedua dikaitkan dengan kebutuhan dari seseorang untuk menghindari ketidaknyamanan dalam pekerjaan yang dikenal dengan faktor kebersihan (hygiene factors).

Yang termasuk dalam faktor motivasi yaitu rasa pencapaian pribadi, pengakuan, pekerjaan itu sendiri, tanggung jawab, kesempatan untuk maju, dan kemungkinan untuk berkembang dan mendapat promosi. Faktor motivasi menyebabkan sikap kerja yang ditunjukkan oleh seseorang menjadi positif sehingga kepuasan kerja yang dirasakannya akan mengalami peningkatan (Herzberg, 1966; Alshmemri et al., 2017). 
Sedangkan faktor kebersihan (hygiene factors) meliputi kompensasi yang diterima dari perusahaan, kebijakan dan administrasi perusahaan, hubungan interpersonal yang baik, keamanan dalam bekerja, dan pengawasan oleh pimpinan (Herzberg, 1966; Alshmemri et al., 2017). Jika faktor motivasi 'bekerja' untuk meningkatkan kepuasan kerja, maka faktor kebersihan 'bekerja' untuk mengurangi ketidakpuasan kerja. Sehingga jika seseorang tidak memiliki faktor motivasi maka tidak berarti ia mengalami ketidakpuasan kerja, tetapi jika seseorang tidak memiliki faktor kebersihan maka sudah pasti ia akan mengalami penurunan kepuasan kerja atau dengan kata lain mengalami ketidakpuasan kerja.

\section{Definisi Konseptual Variabel}

Kompensasi adalah suatu alat yang dapat memajukan tujuan organisasi dengan memberikan imbalan. Imbalan tersebut dapat berwujud maupun tidak berwujud yang diberikan secara adil sebagai bentuk tukaran atas kontribusi yang telah dilakukan karyawan yang kemudian bertujuan untuk meningkatkan motivasi dan kepuasan kerja karyawan tersebut.

Kepemimpinan adalah salah satu fungsi dari manajemen yang bertujuan untuk mencapai tujuan organisasi. Dilakukan dengan cara membujuk, mempengaruhi, dan memotivasi individu lain, dimana hal tersebut dilakukan oleh seseorang yang disebut sebagai pemimpin.

Kepuasan kerja adalah suatu perasaan emosional yang dirasakan oleh seseorang terhadap pekerjaannya, baik itu perasaan yang menyenangkan ataupun tidak menyenangkan, yang bersumber dari dalam maupun luar diri karyawan yang dapat mempengaruhi produktivitasnya dalam bekerja. Tanggapan dari seorang individu terhadap pekerjaannya, pengawasan yang dilakukan oleh pemimpin, dan aspirasi yang diberikan dapat menjadi fokus bagi suatu organisasi dalam meningkatkan kepuasan kerja.

\section{Hubungan Antara Variabel Hubungan antara Kompensasi dengan Kepuasan Kerja}

Dalam penelitian yang dilakukan Dhermawan et al., (2012) dikatakan bahwa kompensasi memiliki pengaruh terhadap kepuasan kerja karyawan. Menurutnya karyawan yang menerima kenaikan kompensasi akan merasa lebih puas dalam pekerjaannya dibandingkan yang tidak. Semakin kecil kompensasi yang diberikan oleh suatu perusahaan maka kemungkinan penurunan kepuasan kerja karyawan akan semakin tinggi.

Selanjutnya menurut Mindari (2018), dalam meningkatkan kepuasan kerja karyawan, maka perusahaan atau organisasi sebaiknya memperhatikan dan meningkatkan kompensasi yang diberikan secara berkala, dan besaran kompensasi yang diberikan sebaiknya sesuai dengan ketentuan perundang-undangan yang berlaku mengenai pemberian kompensasi tersebut. Dalam pemberian kompensasi, peran pemimpin yang adil dan bertanggung jawab juga diperlukan untuk meningkatkan kepuasan kerja.

\section{Hubungan antara Kepemimpinan dengan Kepuasan Kerja}

Menurut Pawirosumarto et al., (2017), seorang pemimpin yang menunjukkan kepemimpinannya dengan memberikan tugas kepada karyawan sesuai dengan prosedur dan terstuktur dengan baik dapat meningkatkan kepuasan kerja, karena karyawan merasa lebih baik dalam hal mendapatkan pengawasan. Sedangkan menurut Reskantika et al., (2019) kepemimpinan memiliki pengaruh terhadap kepuasan kerja terlihat dengan adanya evaluasi yang dilakukan oleh pemimpin terhadap hasil kerja yang dilakukan oleh karyawan, respon pemimpin terhadap keluhan dari karyawan, pemberian rewards kepada karyawan yang berprestasi, dan memberikan peran kepada karyawan untuk memecahkan masalah. Keputusan tidak hanya berada ditangan pemimpin saja, tetapi juga melibatkan karyawan dalam pengambilan keputusan sehingga kepuasan kerja karyawan dapat meningkat. 


\section{Penelitian Relevan}

Mindari (2018) dalam penelitiannya menyatakan bahwa kompensasi dan kepemimpinan memiliki pengaruh yang signifikan terhadap kepuasan kerja. Hasil penelitian Dhermawan et al., (2012) menunjukkan bahwa kompensasi berpengaruh signifikan terhadap kepuasan kerja. Penelitian Ashraf (2020) menunjukkan bahwa kompensasi berpengaruh signifikan terhadap kepuasan kerja. Namun dalam penelitian yang dilakukan Khair (2019) menunjukkan kompensasi tidak berpengaruh signifikan terhadap kepuasan kerja. Selanjutnya penelitian Pawirosumarto et al., (2017) dan Reskantika et al., (2019) menunjukkan kepemimpinan berpengaruh signifikan terhadap kepuasan kerja. Sari et al., (2014) dalam penelitiannya juga menyatakan bahawa kepemimpinan berpengaruh signifikan terhadap kepuasan kerja.

\section{Kerangka Pemikiran dan Hipotesis}

Dalam meningkatkan kepuasan kerja karyawan maka diperlukan adanya kompensasi dan kepemimpinan yang baik dalam suatu perusahaan. Kompensasi yang diberikan oleh perusahaan sebaiknya berdasarkan dengan ketentuan perundang-undangan yang berlaku dan sesuai dengan harapan dari karyawan. Dalam pemberian kompensasi harus dilakukan secara adil agar tidak terjadi kesalahpahaman diantara karyawan lainnya. Karyawan yang telah mendapat kompensasi yang sesuai maka akan mengalami perubahan dalam hal sikap dan perilakunya dalam bekerja. Sehingga karyawan dapat merasakan kepuasan dalam bekerja dan lebih termotivasi dalam melakukan pekerjaannya dengan baik untuk mencapai tujuan dari organisasi dan kemudian dapat meningkatkan komitmen mereka untuk tetap setia pada organisasi tersebut.

Peran kepemimpinan dalam meningkatkan kepuasan kerja karyawan juga tidak kalah penting dibandingkan dengan pemberian kompensasi. Karyawan yang memiliki pemimpin dengan respon dan tanggapan yang baik terhadap bawahannya, memberikan evaluasi terhadap hasil kerja yang telah dilakukan, dan melibatkan karyawan dalam segala kegiatan organisasi dapat meningkatkan kepuasan kerja dari karyawan tersebut. Kepemimpinan yang dimiliki dalam suatu organisasi dapat menjadi salah satu penentu tercapainya tujuan dari organisasi tersebut. Pemimpin yang disenangi karyawan sehingga dapat meningkatkan kepuasan kerjanya, akan melakukan setiap pekerjaan yang diberikan dengan senang hati dan menghasilkan kinerja yang baik bagi organisasi. Dari pemaparan yang telah disebutkan sebelumnya, maka dapat dibuat model penelitian seperti pada gambar 1 di bawah ini.

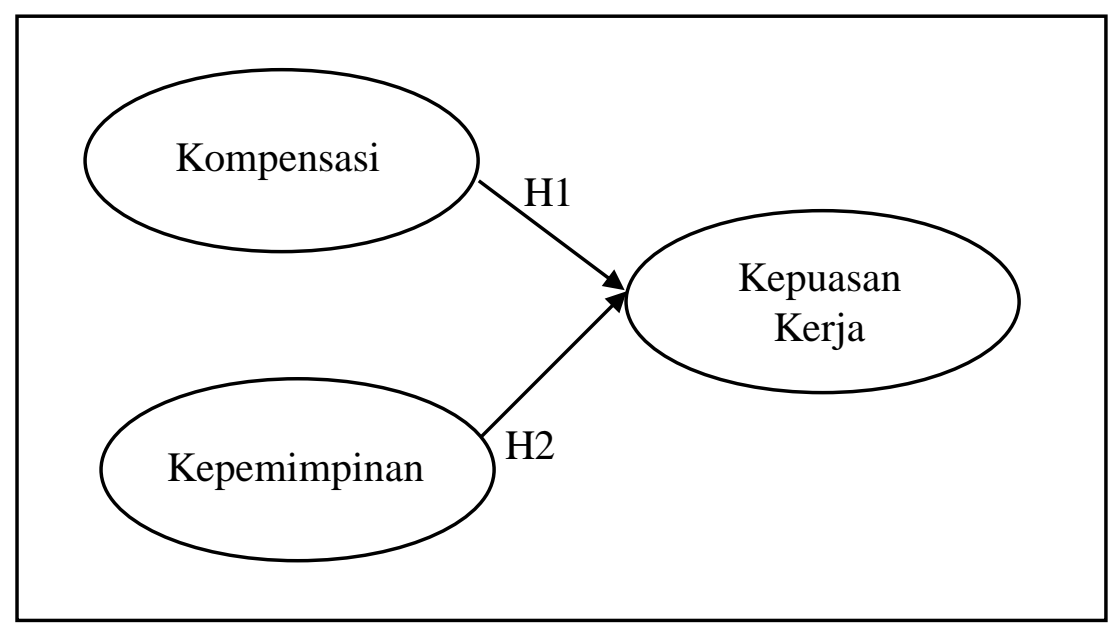

Gambar 1. Model Penelitian

Adapun hipotesis yang didapat dari model penelitian tersebut ialah:

H1: Terdapat pengaruh yang positif dan signifikan antara kompensasi terhadap kepuasan kerja. $\mathrm{H} 2$ : Terdapat pengaruh yang positif dan signifikan antara kepemimpinan terhadap kepuasan kerja. 


\section{METODOLOGI}

Desain penelitian yang digunakan dalam penelitian ini bersifat deskriptif dengan teknik pengumpulan data menggunakan metode cross-sectional design. Dalam proses pengumpulan sampel, penelitian ini menggunakan teknik dari non-probability sampling yaitu dengan convenience sampling dan jumlah sampel yang diambil sebanyak 100 responden. Di mana jumlah sampel tersebut telah sesuai dengan pendapat dari Roscoe yaitu sampel yang tepat dalam suatu penelitian berkisar dari 30 sampai dengan 500 sampel (Sekaran dan Bougie, 2016).

Penelitian ini menggunakan data primer yang diperoleh melalui kuesioner online Google Form yang kemudian disebarkan melalui Whatsapp kepada calon responden yang bekerja pada PT X. Data-data kemudian dikumpulkan ke dalam Microsoft excel, lalu diolah menggunakan software SmartPLS versi 3.3.2.

Adapun subyek yang diteliti yaitu karyawan yang bekerja pada PT X di Jakarta yang diuraikan berdasarkan jenis kelamin, umur, pendidikan terakhir, dan divisi atau bagiannya. Sedangkan untuk obyek yang diteliti yaitu kompensasi, kepemimpinan, dan kepuasan kerja.

\section{HASIL ANALISIS DATA}

Dari 100 responden, 62 orang wanita dan sisanya 38 orang pria. Sebagian besar responden berumur 20 tahun sampai 30 tahun (56 orang, 56\%), berumur 31 tahun sampai 40 tahun sebanyak 35 orang (35\%), dan sisanya yang berumur 41 tahun sampai 50 tahun ( 9 orang, $9 \%$ ). Tidak ada responden yang berumur lebih dari 50 tahun. Pendidikan terakhir dari Sebagian besar responden yaitu SMA/sederajat sebanyak 60 orang (60\%), berpendidikan terakhir sarjana (S1) sebanyak 38 orang (38\%), dan sisanya sebanyak 2 orang (2\%) berpendidikan terakhir magister (S2). Tidak ada responden yang berpendidikan terakhir doktor (S3).

Sebanyak 16 orang responden $(16 \%)$ bekerja pada divisi atau bagian marketing, untuk divisi teknisi dan gudang memiliki jumlah responden yang sama masing-masing sebanyak 11 orang (11\%), dan untuk divisi admin sebanyak 10 orang responden (10\%). Pada divisi keuangan, driver, dan manajemen klinik, jumlah responden yang didapat masing-masing sebanyak 9 orang (9\%), bagian design sebanyak 7 orang (7\%), bagian pajak sebanyak 6 orang (6\%), bagian IT sebanyak 4 orang (4\%), dan bagian receiptionist sebanyak 2 orang (2\%). Responden pada bagian legalitas (POM) serta office boy/girl mendapat jumlah responden yang sama yaitu sebanyak 3 orang $(3 \%)$.

\section{Hasil Analisis Validitas dan Reliabilitas}

Pada penelitian ini, data responden yang telah dikumpulkan, dianalisis dengan menggunakan Partial Least Square (PLS) yang merupakan salah satu metode analisis data menggunakan Structural Equation Modelling (SEM). Pengolahan data dengan pendekatan PLSSEM akan dilakukan dengan menggunakan software SmartPLS versi 3.3.2. Dalam uji validitas akan dilakukan pengujian dengan convergent validity dan discriminant validity. Sedangkan dalam uji reliabilitas akan dilakukan pengujian dengan konsistensi internal dan reliabilitas indikator. 
Tabel 1.

Construct Reliability and Validity

\begin{tabular}{|ccccc|}
\hline & $\begin{array}{c}\text { Cronbach's } \\
\text { Alpha }\end{array}$ & rho_A & $\begin{array}{c}\text { Composite } \\
\text { Reliability }\end{array}$ & $\begin{array}{c}\text { Average Variance } \\
\text { Extracted (AVE) }\end{array}$ \\
Kompensasi & 0.853 & 0.860 & 0.901 & 0.695 \\
Kepemimpinan & 0.825 & 0.836 & 0.883 & 0.654 \\
Kepuasan Kerja & 0.813 & 0.839 & 0.887 & 0.723 \\
\hline
\end{tabular}

Berdasarkan tabel 1, dapat dijelaskan bahwa hasil AVE dari setiap variabel memiliki nilai lebih besar dari 0,5 sehingga variabel kompensasi, kepemimpinan, dan kepuasan kerja sudah memenuhi kriteria dan telah lolos pengujian convergent validity dan dapat diikutsertakan dalam penelitian ini. Hal tersebut sesuai dengan pendapat dari Bagozzi dan Yi (1988) yang menyatakan jika nilai AVE setiap variabel lebih besar dari 0,5 (AVE > 0,50) maka variabel tersebut dapat diikutsertakan.

Selanjutnya dari hasil composite reliability menunjukkan bahwa nilai dari setiap variabel lebih besar dari 0,6. Hal tersebut sudah sesuai dengan pendapat Malhotra (2009) yang menyatakan untuk menilai reliabilitas konstruk, maka nilai composite reliability harus lebih besar dari 0,6 .

Tabel 2.

Fornell-Larcker Criterion

\begin{tabular}{cccc|}
\hline & Kompensasi & Kepemimpinan & $\begin{array}{c}\text { Kepuasan } \\
\text { Kerja }\end{array}$ \\
Kompensasi & 0.834 & & \\
Kepemimpinan & 0.642 & 0.809 & \\
Kepuasan Kerja & 0.531 & 0.661 & 0.850 \\
\hline
\end{tabular}

Selanjutnya dalam tabel 2, berdasarkan kalkulasi pada aplikasi SmartPLS menunjukkan seluruh indikator telah memenuhi kriteria fornell-larcker karena nilai akar kuadrat AVE dari setiap konstruk lebih besar dari nilai korelasi antar konstruk (Hanseler et al., 2009).

\section{Hasil Uji Multikolinieritas}

Tabel 3.

Hasil Uji Multikolinieritas

\begin{tabular}{|cc|}
\hline Variabel & VIF \\
Kompensasi & 1.700 \\
Kepemimpinan & 1.700 \\
\hline
\end{tabular}

Berdasarkan hasil uji multikolinieritas yang dapat dilihat pada tabel di atas, tidak terdapat korelasi antar variabel independen yakni kompensasi dan kepemimpinan yang memiliki nilai VIF lebih besar dari 5. Hasil tersebut berarti bahwa tidak terjadi multikolinieritas antar variabel independen dalam penelitian ini dan telah memenuhi kriteria dari Hair et al., (2011) yang menyatakan nilai VIF harus lebih kecil dari 5 (VIF $<5$ ).

Hasil Uji Model Struktural (Inner Model Analysis) 
Uji model struktural dilakukan untuk menguji hipotesis yang dirumuskan dalam penelitian. Kriteria yang digunakan dalam penelitian ini untuk menganalisis model struktural yaitu uji koefisien determinasi $\left(\mathrm{R}^{2}\right)$ dan predictive relevance $\left(\mathrm{Q}^{2}\right)$.

\section{Tabel 4.}

Hasil Pengujian Koefisien Determinasi $\left(\mathbf{R}^{2}\right)$

\begin{tabular}{|ccc|}
\hline & R Square & R Square Adjusted \\
Kepuasan Kerja & 0.456 & 0.445 \\
\hline
\end{tabular}

Berdasarkan hasil pengujian koefisien determinasi pada tabel di atas, maka dapat diketahui bahwa nilai $\mathrm{R}^{2}$ sebesar 0,456 atau jika dipersentasekan sebesar 45,6\%. Yang artinya kompensasi dan kepemimpinan memiliki kontribusi moderat terhadap kepuasan kerja sebesar 45,6\%. Sedangkan sisanya sebesar 54,4\% kontribusi kepuasan kerja berasal atau ditentukan oleh variabel lain yang tidak termasuk dalam penelitian ini.

Tabel 5.

Hasil Pengujian Predictive Relevance $\left(\mathrm{Q}^{2}\right)$

\begin{tabular}{cccc|}
\hline & SSO & SSE & $\mathrm{Q}^{2}(=1-$ SSE/SSO $)$ \\
Kompensasi & 400.000 & 400.000 & \\
Kepemimpinan & 400.000 & 400.000 & \\
Kepuasan Kerja & 300.000 & 213.073 & 0.290 \\
\hline
\end{tabular}

Dalam tabel 5 di atas menunjukkan nilai $Q^{2}$ sebesar 0,290 yang berarti bahwa variabel kompensasi dan kepemimpinan dapat memprediksi variabel kepuasan kerja dengan baik karena telah memenuhi kriteria menurut Hair et al., (2011) yang menyatakan jika nilai $\mathrm{Q}^{2}$ lebih besar dari nol $\left(\mathrm{Q}^{2}>0\right)$ maka variabel dependen tersebut dapat dinyatakan memprediksi variabel independen.

\section{Hasil Pengujian Hipotesis Penelitian}

Ringle et al., (2018) menyatakan bahwa pengujian hipotesis dalam suatu penelitian dengan menggunakan metode analisis PLS-SEM dapat dilakukan dengan melakukan uji effect size $\left(\mathrm{f}^{2}\right)$, path coefficients, significance test (t-test atau $p$-value), dan uji goodness of fit model (GoF Index).

Tabel 6.

Hasil Pengujian Effect Size $\left(\mathbf{f}^{2}\right)$

\begin{tabular}{|c|c|c|}
\hline & Kompensasi Kepemimpinan & Kepuasan Kerja \\
\hline Kompensasi & & 0.035 \\
\hline Kepemimpinan & & 0.321 \\
\hline Kepuasan Kerja & & \\
\hline
\end{tabular}

Berdasarkan tabel 6, dapat dijelaskan bahwa variabel kompensasi dan kepemimpinan memiliki efek perubahan yang tergolong sedang terhadap kepuasan kerja. Hal tersebut berdasarkan kriteria dari Sarstedt et al., (2013) yang menyatakan jika nilai $\mathrm{f}^{2}$ lebih besar dari 0,02 dan lebih kecil dari $0,35\left(0,02>\mathrm{f}^{2}<0,35\right)$ maka variabel independen memiliki efek sedang terhadap variabel dependennya. 
Tabel 7.

Hasil Path Coefficients dan Significance Test

\begin{tabular}{|llcc|}
\hline & $\begin{array}{l}\text { Path } \\
\text { Coefficients }\end{array}$ & T Statistics & P Values \\
X1 (K) -> Y (KK) & 0.181 & 1.307 & 0.192 \\
X2 (KP) -> Y (KK) & 0.545 & 5.866 & 0.000 \\
\hline
\end{tabular}

Berdasarkan hasil path coefficients pada tabel di atas memperlihatkan seluruh variabel independen merupakan prediktor positif terhadap variabel dependen. Variabel kompensasi merupakan prediktor positif terhadap kepuasan kerja dengan nilai sebesar 0,181. Dan untuk variabel kepemimpinan juga merupakan prediktor positif terhadap kepuasan kerja dengan nilai sebesar 0,545 .

Selanjutnya berdasarkan pada tabel $7 \mathrm{di}$ atas menunjukkan nilai $t$-statistics untuk variabel independen kompensasi sebesar 1,307 dengan nilai p-value sebesar 0,192. Di mana nilai tersebut kurang dari 1,96 ( $t$-statistics $<1,96 ; \alpha=5 \%$ ), yang berarti bahwa tidak terdapat pengaruh yang signifikan antara kompensasi terhadap kepuasan kerja. Sedangkan untuk variabel independen kepemimpinan memiliki nilai t-statistics sebesar 5,866 dan nilai $p$-value sebesar 0,000 . Yang memiliki arti bahwa terdapat pengaruh yang signifikan antara kepemimpinan terhadap kepuasan kerja karena nilai t-statistics lebih besar dari 1,96 (t-statistics $>1,96 ; \alpha=5 \%$ ).

Dan untuk pengujian goodness of fit index (GoF Index) dilakukan dengan mengakarkuadratkan perkalian dari nilai average communality index (AVE) dan average $R$-Square $\left(\mathrm{R}^{2}\right)$. Nilai $\left(\overline{A V E}=\frac{0,695+0,654+0,723}{3}\right)$ dan nilai $\overline{R^{2}}$ sebesar 0,456 . Setelah mendapat nilai yang dibutuhkan, maka nilai GoF Index dapat dihitung secara manual dengan rumus berikut

$$
\mathrm{GoF}=\sqrt{\overline{A V E} \times \overline{R^{2}}}=\sqrt{0,690 \times 0,456}=0,561
$$

Dari hasil perhitungan tersebut, didapat nilai GoF sebesar 0,561 sehingga dapat digolongkan model penelitian ini memiliki tingkat ketepatan yang besar. Hal tersebut sesuai berdasarkan kategori GoF menurut Wetzels et al., (2009) yang menyatakan jika nilai GoF lebih besar dari $0,36(\mathrm{GoF}>0,36)$ maka model penelitian yang dilakukan memiliki tingkat ketepatan yang besar

\section{DISKUSI}

\section{Pengaruh Kompensasi terhadap Kepuasan Kerja}

Hasil penelitian ini menunjukkan bahwa kompensasi memiliki pengaruh yang positif namun tidak signifikan terhadap kepuasan kerja. Hasil penelitian ini didukung oleh penelitian yang dilakukan oleh Khair (2019) yang menyatakan bahwa kompensasi tidak memiliki pengaruh yang signifikan terhadap kepuasan kerja. Hasil seperti ini dapat terjadi apabila karyawan merasa bahwa kebutuhannya telah tercukupi. Dengan terpenuhinya segala harapan serta kebutuhan pribadi karyawan dan kebutuhan anggota keluarganya, maka kompensasi seperti penghargaan atau bonus tidak lagi berpengaruh terhadap kepuasan kerjanya.

\section{Pengaruh Kepemimpinan terhadap Kepuasan Kerja}

Hasil penelitian ini menunjukkan bahwa kepemimpinan memiliki pengaruh yang positif dan signifikan terhadap kepuasan kerja. Hal ini berarti jika seorang pemimpin dalam suatu perusahaan menunjukkan sikap kepemimpinannya dengan baik maka dapat meningkatkan kepuasan kerja yang dirasakan karyawan. Hasil penelitian ini sejalan dengan penelitian sebelumnya yang dilakukan oleh Sari et al., (2014), Pawirosumarto et al., (2017), Mindari 
(2018), dan Reskantika et al., (2019) yang menyatakan kepemimpinan memiliki pengaruh yang signifikan terhadap kepuasan kerja. Kepemimpinan yang dimiliki dalam suatu perusahaan harus dapat menata pola pikir dari karyawan agar dapat menaati dan melakukan setiap pekerjaan sesuai dengan norma dan aturan yang berlaku. Selain itu, kepemimpinan yang baik dapat terlihat dari sikap seorang pemimpin dalam melakukan pengawasan, mendelegasikan wewenang, memotivasi, dan melibatkan bawahan dalam pengambilan keputusan. Kepuasan kerja yang dirasakan karyawan dapat meningkat apabila pimpinannya dapat memberikan tugas atau mendelegasikan wewenang sesuai dengan prosedur yang ada dan terstruktur dengan baik, sehingga karyawan akan merasa mendapat pengawasan atas setiap pekerjaan yang dilakukannya. Pengadaan evaluasi terhadap hasil kerja yang dilakukan karyawan serta melibatkan karyawan dalam proses pengambilan keputusan juga menjadi salah satu indikator yang memberikan peningkatan terhadap kepuasan kerja yang dirasakan karyawan.

\section{PENUTUP}

Penelitian ini tentunya memiliki beberapa keterbatasan, diantaranya yaitu keterbatasan waktu, jumlah responden, serta variabel yang digunakan. Waktu yang relatif singkat dalam melakukan penelitian mengakibatkan keterbatasan dalam pengumpulan jumlah responden. Sehingga mungkin kurang merepresentasikan pendapat dari karyawan yang bekerja pada PT X secara keseluruhan. Maka dari itu beberapa saran yang dapat diberikan antara lain kepada PT X sebaiknya memperhatikan sikap kepemimpinan yang ditunjukkan kepada karyawannya, karena dalam penelitian ini kepemimpinan terbukti signifikan mempengaruhi kepuasan kerja karyawan. Penelitian selanjutnya disarankan untuk menambah variabel independen yang diteliti, seperti turnover intention, lingkungan kerja, dan lain sebagainya.

\section{DAFTAR PUSTAKA}

Alshmemri, M., Shahwan-Akl, L., \& Maude, P. (2017) "Herzberg's two-factor theory". Life Science Journal, 14(5), 12-16.

Ashraf, M. A. (2020) "Demographic factors, compensation, job satisfaction and organizational commitment in private university: an analysis using SEM". Journal of Global Responsibility, 11(4), 407-436.

Bagozzi, R. P., \& Yi, Y. (1988) "On the evaluation of structural equation models". Journal of the academy of marketing science, 16(1), 74-94

Becker, J. M., Ringle, C. M., \& Sarstedt, M. (2018) "Estimating moderating effects in PLS-SEM and PLS-SEM: Interaction term generation data treatment". Journal of Applied Structural Equation Modeling, 2(2), 1-21.

Dhermawan, A. A. N. B., Sudibya, I. G. A., \& Utama, I. W. M. (2012) "Pengaruh motivasi, lingkungan kerja, kompetensi, dan kompensasi terhadap kepuasan kerja dan kinerja pegawai di lingkungan kantor Dinas Pekerjaan Umum Provinsi Bali”. Jurnal Manajemen, Strategi Bisnis, dan Kewirausahaan, 6(2), 173-184.

Hair, J. F., Ringle, C. M., \& Sarstedt, M. (2011) "PLS-SEM: Indeed a silver bullet". Journal of Marketing theory and Practice, 19(2), 139-152.

Hair, J. F., Ringle, C. M., \& Sarstedt, M. (2013) "Partial least squares structural equation modeling: Rigorous applications, better results and higher acceptance". Long range planning, 46(1-2), 1-12.

Hasibuan, M. S. (2006) Organisasi dan motivasi: dasar peningkatan produktivitas. Jakarta: Bumi Aksara. 
Henseler, J., Ringle, C. M., \& Sinkovics, R. R. (2009) "The use of partial least squares path modeling in international marketing". Advances in International Marketing, 20, 277-319.

Herzberg, F. (1966) Work and the nature of man. New York: World Publishing.

Khair, H. (2019) "Pengaruh kepemimpinan dan kompensasi terhadap kepuasan kerja melalui motivasi kerja". Maneggio: Jurnal Ilmiah Magister Manajemen, 2(1), 69-88.

Kompas. (2018) Kurang Apresiasi, 30 Persen Pekerja Indonesia Ingin Pindah Kerja. Retrieved October, 2020, from https://lifestyle.kompas.com/read/2018/01/02/214530820/kurangapresiasi-30-persen-pekerja-indonesia-ingin-pindah-kerja.

Malhotra, N. K. (2009) Riset pemasaran, edisi keempat, jilid 1. Jakarta: PT Indeks.

Mindari, E. (2018) "Pengaruh kompensasi, lingkungan kerja dan kepemimpinan terhadap kepuasan kerja karyawan PT. Bisma Hamirah Palembang”. Jurnal Ecoment Global, 3(1), $35-41$.

Pawirosumarto, S., Sarjana, P. K., \& Gunawan, R. (2017) "The effect of work environment, leadership style, and organizational culture towards job satisfaction and its implication towards employee performance in Parador Hotels and Resorts, Indonesia". International Journal of Law and Management, 59(6), 1337-1358.

Priherdityo, E. (2016) Survei: 77 Persen Karyawan Tidak Puas Tunjangan Kerja. Retrieved October, 2020, from https://www.cnnindonesia.com/gaya-hidup/20160127134134-277107059/survei-77-persen-karyawan-tidak-puas-tunjangan-kerja.

Reskantika, R., Paminto, A., \& Ulfah, Y. (2019) "Pengaruh gaya kepemimpinan dan budaya organisasi serta motivasi terhadap kepuasan kerja dan komitmen organisasi". Jurnal Manajemen, 11(2), 195-202.

Safitri, D. E., Hariyadi, S., \& Prihastuty, R. (2014) "Influence of the compensation by the company giving satisfaction to employee morale in TPKS (Pengaruh kepuasan pemberian kompensasi oleh perusahaan terhadap semangat kerja karyawan di TPKS)". Journal of Social and Industrial Psychology, 3(1), 13-19.

Sari, L., Sampurno, S., \& Wahyono, D. (2014) "Pengaruh kepemimpinan dan budaya organisasi terhadap kepuasan kerja karyawan di Yogyakarta”. Jurnal Manajemen Dan Pelayanan Farmasi (Journal of Management and Pharmacy Practice), 4(1), 33-38.

Sekaran, U., \& Bougie, R. (2016) Research methods for business: A skill building approach. United States: John Wiley \& Sons.

Wetzels, M., Odekerken-Schröder, G., \& Van Oppen, C. (2009) "Using PLS path modeling for assessing hierarchical construct models: Guidelines and empirical illustration". MIS Quarterly: Management Information Systems, 33(1), 177-195. 